\title{
Introduction to the special issue: theory of food webs
}

\author{
Alan Hastings ${ }^{1} \cdot$ Kevin S. McCann ${ }^{2} \cdot$ Peter C. de Ruiter $^{3}$
}

Received: 11 January 2016 / Accepted: 11 January 2016/Published online: 20 January 2016

(C) Springer Science+Business Media Dordrecht 2016

"Why are there so many species on earth?" It is one of the most fundamental questions in understanding life on earth. The question becomes even more prominent when we rephrase it into "Why are there so many species anywhere we are: oceans, forests, fresh water streams, lakes, soils, grasslands, agricultural land." Almost everywhere, we see many species living together. One answer of course is "niche differentiation" powerfully counteracting the Darwinian concept of competitive exclusion and the survival of the fittest. The middle of the last century saw the advent of using community perspectives to approach this question as exemplified by the contributions of Robert MacArthur. He argued (MacArthur $1955)$ that "Biodiversity begets stability": when a species is part of a species-rich community, it will be better able to withstand environmental change and disturbance because of buffering effects through the complex network of biological interactions with other species in the community. This concept is a mix of deep knowledge of our living environment and the biological intuition by one of the greatest naturalists of our time.

The "Diversity begets stability" concept gained enormous momentum through the seminal theoretical work by Robert May (1972, 1973). May showed that aspects of biological complexity, i.e., the number of species and the frequency of

\section{Alan Hastings}

amhastings@ucdavis.edu

1 Department of Environmental Science and Policy, University of California, Davis, CA 95616, USA

2 Department of Integrative Biology, University of Guelph, Guelph, ON, Canada

3 Institute of Biodiversity and Ecosystem Dynamics, University of Amsterdam, P.O. Box 94248, 1090 GE Amsterdam, The Netherlands interactions among the species ("connectance"), constrains stability. The apparent contradiction between the notion of MacArthur and the model results of May has been a central focus of ecology ever since. The model results of May also challenge what we see in nature: long-term co-existence and survival of many species living together in almost all habitats on our planet.

The models of May represent communities with random types of interactions (predator-prey, competition, facilitation, mutualism, commensalism) with random strength of the interactions. One of the first steps in rebuilding and reformulating the random kind of May's models toward more realistic nonrandom models has been a redefinition of the biological community represented by the models in terms of food webs. Food webs are diagrams of biological communities highlighting the trophic interactions between resource species and consumer species. Food web interactions are key in understanding community structure, dynamics, and stability, because trophic interactions are crucial for the survival of both resource and consumer species.

Two lines of food web ecology have developed. The first line of research starts from models and investigates what kind of model modification leads to a more positive relationship between biological diversity and community stability. These modifications include frequency of trophic cycles (A eats B, B eats C, and C eats A) (DeAngelis 1975), frequency of omnivory (Pimm and Lawton 1978), and asymmetry of positive versus negative interaction strength (Pimm and Lawton 1977; Yodzis 1981). The pioneering studies of Peter Yodzis showed that stability constraints could be strongly relieved by including biological realistic interaction strength patterns in the models (Yodzis 1981) and showing that complex food web structures generates counter-intuitive results, e.g., that suppression of a predator may lead to lower prey numbers instead of higher prey numbers (Yodzis 1988). This latter 
finding has become the starting point of research on the idiosyncratic nature of the effects of manipulation and perturbation in food webs (Karieva and Levin 2003). This research direction has continued for more than 50 years generating tremendous insights in how non-random food web structures may allow for ecological stability.

The model results of May also challenge empiricists. By exhaustive observations on inter-tidal food webs, Robert Paine (1980) formulated three types of food web diagrams: connectedness webs, energy flux webs, and functional webs. Connectedness webs picture food web in a binary way, i.e., in terms of presence or absence of trophic species/groups and trophic interactions. Energy flux webs are more quantitative by specifying the pools and flows of material and energy in species biomass and feeding rates. Functional webs weigh the trophic groups and interactions on the basis of their impact on food web structure and stability. The observations by Paine clearly show that within food webs, there is a huge variation in material pools and flows, and that this variation does not necessarily corresponds with the importance of groups or links to food web stability, i.e., trophic interactions that represent small material flows can be key-interactions in food web stability. The work by Paine has been extremely influential because it led to many empirically based food web models that allowed us to begin to understand how real ecosystem structure can play a crucial role in the stability of species-rich communities. Furthermore, this empirically driven theory found that such realistic patterns can act to relieve the constraints on stability as suggested by models with a more random structure and interactions strength.

Since May (1973), a tradition of decadal food web symposia started with accompanying books summarizing the outcome of these meetings. The first food web symposium was convened at Gatlinburg, North Carolina, in 1982 (DeAngelis et al. 1983: "Current Trends in Food Web Theory"). That symposium highlights theoretical studies focusing on the complexity-stability relationship. The second food web symposium was held at Pingree Park, Colorado, in 1993 (Polis and Winemiller 1996: "Food webs: Integration of patterns and dynamics"). Topics addressed are patterns in interaction strength, indirect effects, keystone species, spatial variation, and a search for more detailed and accurate food web descriptions. The third was held in November 2003 in Schloss Rauischolzhausen, Germany. Issues characteristic for this meeting are effects of environmental change and the functional implications of biodiversity (De Ruiter et al. 2005: "Dynamic Food Webs: Multispecies Assemblages, Ecosystem Development and Environmental Change"). The fourth (November 2013) was also held in Schloss Rauischolzhausen, Germany, with a strong focus on the role of food web science in solving societal issues like environmental and climate change, biodiversity preservation, and sustainable agriculture and fisheries (Moore et al. 2016: "Adaptive Food Webs: Science for Impact"). Apart from these volumes presenting the state-of-the-art in food web ecology at that time, another cornerstone in food web ecology is the special issue of the Philosophical Transactions of the Royal Society B "Food web assembly and collapse: mathematical models and implications for conservation" (Dobson et al. 2009) addressing issues like how to incorporate parasitic interactions in food webs, invasions, and the role of stoichiometry.

The papers in this special issue of Theoretical Ecology on food webs build on these earlier efforts and provide an up to date view of new and exciting directions in food web research. Notable among the new directions are novel ways of understanding the impact of realistic biological interactions on the interactions in model food webs and consequent implications for food web complexity and stability. Another dominant theme running through the papers here is the importance of explicitly including space and time in the development of food web theory.

\section{References}

De Ruiter PC, Moore JC, Wolters V (2005) Dynamic food webs: multispecies assemblages, ecosystem development, and environmental change, vol 3, Theoretical Ecology. Academic, Cambridge

DeAngelis DL (1975) Stability and connectance in food web models. Ecology 56:238-243

DeAngelis DL, Post W, Sugihara G (1983) Current trends in food web theory. Oak Ridge National Laboratory, Oak Ridge

Dobson A, Allesina S, Lafferty K, Pascual M (2009) Food-web assembly and collapse: mathematical models and implications for conservation. Philosophical Transactions of the Royal Society B 364:18031806, 1524

Karieva P, Levin SA (2003) The importance of species: perspectives on expendability and triage. Princeton University Press, Princeton

MacArthur R (1955) Fluctuations of animal populations, and a measure of community stability. Ecology 36:533-536

May RM (1972) Will a large complex system be stable? Nature 238: 413-414

May RM (1973) Stability and complexity in model ecosystems, 2nd edn. Princeton University Press, Princeton

Moore JC, de Ruiter PC, McCann KS, Wolters V (2016) Adaptive food webs: science for impact. Cambridge University Press, Cambridge

Paine RT (1980) Food webs: linkage, interaction strength and community infrastructure. J Anim Ecol 49:667-685

Pimm SL, Lawton JH (1977) The number of trophic levels in ecological communities. Nature 268:329-331

Pimm SL, Lawton JH (1978) On feeding on more than one trophic level. Nature 275:542-544

Polis GA, Winemiller KO (Eds) (1996) Food Webs: Integration of patterns and dynamics. Chapman and Hall, New York

Yodzis P (1981) The stability of real ecosystems. Nature 289:674-676

Yodzis P (1988) The indeterminacy of ecological interactions as perceived by perturbation experiments. Ecology 72:1964-1972 